\title{
Characterization of Natural Killer Cells and Cytokines in Maternal Placenta and Fetus of Diabetic Mothers
}

\author{
Cristiane de Castro Pernet Hara, ${ }^{1}$ Eduardo Luzía França, ${ }^{2}$ \\ Danny Laura Gomes Fagundes, ${ }^{2}$ Adriele Ataides de Queiroz, ${ }^{2}$ Marilza Vieira Cunha Rudge, \\ Adenilda Cristina Honorio-França, ${ }^{2}$ and Iracema de Mattos Paranhos Calderon ${ }^{1}$ \\ ${ }^{1}$ Graduate Program in Gynecology, Obstetrics and Mastology, Botucatu Medical School, São Paulo State University (UNESP), \\ 18600-000 São Paulo, SP, Brazil \\ ${ }^{2}$ Institute of Biological and Health Science, Federal University of Mato Grosso, 78600-000 Barra do Garças, MT, Brazil
}

Correspondence should be addressed to Adenilda Cristina Honorio-França; denifran@terra.com.br

Received 26 February 2016; Revised 20 April 2016; Accepted 24 April 2016

Academic Editor: Kurt Blaser

Copyright (C) 2016 Cristiane de Castro Pernet Hara et al. This is an open access article distributed under the Creative Commons Attribution License, which permits unrestricted use, distribution, and reproduction in any medium, provided the original work is properly cited.

\begin{abstract}
The present study characterized natural killer cells and cytokines in diabetic mothers, their placenta, and fetus. In the maternal blood from the hyperglycemic groups, the $\mathrm{CD} 16^{+} \mathrm{CD} 56^{-} \mathrm{NK}$ cells increased, whereas that of $\mathrm{CD} 16^{+} \mathrm{CD} 56^{+}$decreased in gestational diabetes mellitus [GDM] group. Cord blood from type 2 diabetes [DM-2] showed a higher proportion of $\mathrm{CD}_{16}{ }^{+} \mathrm{CD} 56^{-}$and $\mathrm{CD} 6^{-} \mathrm{CD} 56^{+}$. The placental extravillous layer of GDM and DM-2 showed an increase of CD16 ${ }^{+} \mathrm{CD} 56^{-}$cells and, irrespective of region, the proportion of $\mathrm{CD}_{16}{ }^{-} \mathrm{CD}_{5} 6^{+}$cells was higher in mild gestational hyperglycemia [MGH] and GDM and lower in DM-2. IL-2 was lower in maternal blood and IFN- $\gamma$ higher in maternal and cord blood from the GDM group. IL-17 was higher in maternal and cord blood from the DM-2 group. The placental extravillous layer of the MGH showed high levels of IL-4, IL-6, IL-10, IL17 , and IFN- $\gamma$ and low levels of IL- $1 \beta$ and IL-8, whereas the placental villous layer contained high levels of IL-17 and IFN- $\gamma$. The GDM group, irrespective of region, showed higher levels of IL-8. The DM-2 group, irrespective of region, placenta showed high levels of TNF- $\alpha$, IL-17, and IFN- $\gamma$. The hyperglycemia produces an inflammatory environment with a high content of inflammatory cytokines and cells expressing $\mathrm{CD}_{1}{ }^{+}$.
\end{abstract}

\section{Introduction}

During pregnancy, the maternal system undergoes adaptations involving cells and proteins associated with the immune-regulatory function to ensure fetal development. One of the tissues participating in immune-regulation of the maternal-fetal relationship is the placenta, a transient organ responsible for fetal protection, nutrition, breathing, and endocrine control [1]. Placental cells derived from both maternal and fetal organisms express molecules that play a fundamental role in maternal-fetal tolerance [2].

Decidua leukocytes, including macrophages, are a prominent population of $\mathrm{T}$ cells and natural killer (NK) cells [3] recognized by their direct in vitro cytotoxicity. NK cells are characterized as CD16 and CD56 according to the antigens on their surface. More than $95 \%$ of human uterine NK cells
(uNK) do not exhibit cytotoxicity and are phenotypically defined as CD56 [4-6]. These cells can recognize the fetal HLA-G histocompatibility antigen and produce cytotoxicity suppressors $[7,8]$. The balance between peripheral blood NK cells and regulatory NK cells (NKreg) during pregnancy is essential [9].

The profile of NK cells in the decidua is different from that of NK cells in peripheral blood. Other studies report that decidual NK cells produce cytokines such as IFN- $\gamma$, TNF- $\alpha$, and IL- 4 [9]. TNF- $\alpha$, IL- $1 \beta$, and IL- 6 are essential in early pregnancy, but, with the evolution of gestation, high TNF$\alpha$ levels can promote preeclampsia and gestational diabetes mellitus, while low IL-10 levels are associated with preterm birth [10-15]. Therefore, TNF- $\alpha$ production appears to be required for early pregnancy maintenance, whereas IL-10 plays a protective role in fetal development [16]. In diabetic 
mothers, IL-17 levels increase during pregnancy, and the cord blood of their newborns shows low IFN- $\gamma$ levels [17].

In normal pregnancy, IL-4 produced by trophoblasts stimulates Th2 lymphocytes and increases the levels of inhibitory receptors in decidual NK cells, which maintain their inactive phenotype $\left(\mathrm{CD} 16^{-} \mathrm{CD} 56^{+}\right)[7,8]$. The hyperglycemic condition, however, generates a proinflammatory environment capable of affecting fetal development, and the production of inflammatory cytokines can pose a risk to fetal health and promote the development of complications associated with diabetes in pregnancy [16].

The immune response associated with diabetes during pregnancy has yet to be completely understood, and the role of NK cells remains unknown. Diabetes possibly changes the expression of NK cells and cytokines in the maternal-placental-fetal unit. To investigate this hypothesis, the present study characterized the NK cells and cytokines of diabetic mothers, as well as their placentas and fetuses.

\section{Materials and Methods}

Placenta, maternal blood, and cord blood from diabetic mothers was evaluated in a cross-sectional study. The subjects attended the Diabetes and Pregnancy Facility, School of Medicine Obstetrics Course, UNESP, Botucatu, SP. This study was approved by the institutional Research Ethics Committee, and all the subjects gave informed written consent before entering the experimental protocol.

2.1. Subjects. Placenta and blood samples from pregnant women (18-45 years old) were analyzed by maternal glycemic status. Pregnant women with diabetes mellitus type 2 (DM2) were referred to the Service with a confirmed diagnosis. Pregnant women underwent a $75 \mathrm{~g}$ oral glucose tolerance test [OGTT-75 g] [18] and glucose profile (GP) [19], which were applied in parallel between the 24th and 28th weeks of pregnancy. Altered GP were considered when any one value is found equal to or exceeding fasting glycemia of $90 \mathrm{mg} / \mathrm{dL}$ and postprandial level of $130 \mathrm{mg} / \mathrm{dL}$ [20]. The OGTT-75 g was altered when any of the following plasma glucose values are met or fasting glycemia of $92 \mathrm{mg} / \mathrm{dL}$ is exceeded: $1 \mathrm{~h}$ postload level of $180 \mathrm{mg} / \mathrm{dL}$ and $2 \mathrm{~h}$ postload level of $153 \mathrm{mg} / \mathrm{dL}$ [19]. According to the results of the OGTT-75 $\mathrm{g}$ and GP test, 55 pregnant women were classified into the following groups: nondiabetic [ND; normal $75 \mathrm{~g}$ OGTT and GP; $N=15$ ], mild gestational hyperglycemia [MGH; normal $75 \mathrm{~g}$ OGTT and abnormal GP; $N=15$ ], gestational diabetes mellitus [GDM; abnormal $75 \mathrm{~g}$ OGTT in pregnancy; $N=10$ ], and diabetes mellitus type 2 [DM-2; abnormal $75 \mathrm{~g}$ OGTT prior to pregnancy; $N=15$ ] [20].

The subjects continued attending the facility, irrespective of diagnosis, and the hyperglycemic patients followed a specific treatment for glycemic control [19].

2.2. Subject Follow-Up and Characterization. Patients with DM-2 or MGH were evaluated for GP with fasting and pre- and postprandial glycemic levels for 24 hours in twoweek intervals until the 32 nd week and then weekly until delivery. Glycemic control was assessed during pregnancy. Adequate glycemic control during pregnancy was defined as a glycemic mean of $120 \mathrm{mg} / \mathrm{dL}$ or less, and inadequate control was defined as a glycemic mean higher than $120 \mathrm{mg} / \mathrm{dL}$. Thus, pregnant women with $\mathrm{MGH}$ were treated with a diet recommended by a dietitian and exercise; insulin therapy was applied when they had inadequate glycemic control. Patients with DM-2 were treated with a diet, exercise, and insulin therapy since the beginning of the pregnancy [20]. The ND pregnant women did not receive any type of intervention against hyperglycemia control.

2.3. Blood Sampling and Preparation of Blood Cells. Samples of $8 \mathrm{~mL}$ of maternal blood were collected in the morning at 36th week of pregnancy, prior to the beginning of labor. The umbilical cord blood was intradelivery-collected shortly after clamping. The maternal blood and umbilical cord blood were collected in Vacutainer tubes (Becton Dickinson, USA) treated with anticoagulant (EDTA). We centrifuged them at $160 \mathrm{G}$ for $15 \mathrm{~min}$ to separate plasma from the cells. The plasma was stored at $-80^{\circ} \mathrm{C}$ for later cytokines analysis. The isolation procedure was performed by centrifugation (40 min at $160 \times \mathrm{g}$ ), with Ficoll-Paque gradient (density $1.077 \mathrm{~g} / \mathrm{L}$; Sigma Chemical, St. Louis, USA). After centrifugation the supernatant was discarded, and the opaque bands at the interfaces between plasma and Ficoll-Paque-1077 containing cells were collected carefully by aspiration with a siliconized Pasteur pipet and transferred to tubes. NK cells were purified by positive selection with magnetic beads [21]. Cells were resuspended independently in serum-free medium 199 and used immediately for assays of flow cytometer.

2.4. Placenta Sampling and Preparation of Blood Cells. Placentas were collected at the moment of delivery and immediately washed with a saline solution. Samples of villous tissue were taken across the placenta halfway between the maternal and fetal sides and the large vessels were removed leaving only villous tissue $[22,23]$. The basal plate was carefully dissected from the villous tissue and the amniochorionic membrane. Isolation of extravillous tissue was adapted from described procedure for amniochorionic cytotrophoblast isolation [23, 24]. These fragments were immediately stored in liquid nitrogen and later processed for cells separation. Placental fragments were macerated in PBS with Tween 20 supplemented with protease inhibitors $(0.1 \mathrm{mM}$ of phenylmethylsulfonyl fluoride; $0.1 \mathrm{mM}$ of benzethonium chloride, $10 \mathrm{mM}$ of EDTA, 20 UI of aprotinin, and $0.5 \%$ of BSA) in a proportion of $100 \mathrm{mg}$ of tissue/mL, using a homogenizer Power Gen 125 (Fisher Scientific@). The homogenate was filtered and reserved from cytokines quantification and the sediment (cells) was fractioned by centrifugation $(160 \times \mathrm{g}, 40 \mathrm{~min})$ through gradient density. The isolation procedure was performed by Ficoll-Paque (density $1.077 \mathrm{~g} / \mathrm{L}$; Sigma Chemical, St. Louis, USA). After centrifugation the supernatant was discarded, and the opaque bands at the interfaces between PBS and Ficoll-Paque-1077 containing cells were collected carefully by aspiration with a siliconized Pasteur pipet and transferred to tubes. NK cells were purified by positive selection with magnetic beads [21]. The cells were washed twice 
TABLE 1: Clinical data on the pregnant women with different glycemic status (ND: nondiabetic, MGH: mild gestational hyperglycemia, GDM: gestational diabetes mellitus, and DM-2: type 2 diabetes mellitus) and their newborns.

\begin{tabular}{|c|c|c|c|c|}
\hline Parameters & $\begin{array}{c}\mathrm{ND} \\
(N=15)\end{array}$ & $\begin{array}{c}\text { MGH } \\
(N=15)\end{array}$ & $\begin{array}{c}\text { GDM } \\
(N=10)\end{array}$ & $\begin{array}{c}\text { DM-2 } \\
(N=15)\end{array}$ \\
\hline \multicolumn{5}{|l|}{ Mothers } \\
\hline Age (years) & $26.35 \pm 4.20$ & $27.63 \pm 6.93$ & $29.55 \pm 6.55$ & $32.55 \pm 5.94$ \\
\hline Gestational age (weeks) & $39.17 \pm 0.471$ & $38.55 \pm 1.39$ & $38.12 \pm 0.39$ & $37.23 \pm 1.29$ \\
\hline Weight gain & $13.02 \pm 7.25$ & $9.45 \pm 4.78$ & $11.31 \pm 3.75$ & $10.31 \pm 6.75$ \\
\hline BMI-1 & $27.52 \pm 6.17$ & $28.54 \pm 7.05$ & $28.66 \pm 4.60$ & $31.66 \pm 6.96^{*}$ \\
\hline BMI-2 & $31.13 \pm 7.67$ & $31.88 \pm 6.50$ & $32.89 \pm 6.33$ & $34.09 \pm 9.93$ \\
\hline Glucose level (mg/dL) & $81.96 \pm 9.60$ & $93.73 \pm 7.20$ & $104.20 \pm 15.87$ & $\begin{array}{c}105.30 \pm \\
15.87^{*}\end{array}$ \\
\hline HbAlc (\%) & $5.07 \pm 0.46$ & $5.12 \pm 0.44$ & $5.79 \pm 0.89^{*}$ & $5.72 \pm 0.44^{*}$ \\
\hline \multicolumn{5}{|l|}{ Newborn } \\
\hline Glucose (mg/dL) & $77.71 \pm 10.92$ & $73.83 \pm 15.08$ & $59.04 \pm 13.01$ & $63.12 \pm 16.11$ \\
\hline Bilirubin & $1.71 \pm 0.48$ & $1.74 \pm 0.59$ & $1.76 \pm 0.80$ & $1.82 \pm 1.16$ \\
\hline Insulin & $>2$ & $6.77 \pm 2.77$ & $6.65 \pm 2.07$ & $7.39 \pm 5.7$ \\
\hline Ponderal index & $0.028 \pm 0.002$ & $0.028 \pm 0.002$ & $0.028 \pm 0.003$ & $0.028 \pm 0.002$ \\
\hline Placental index & $0.168 \pm 0.037$ & $0.183 \pm 0.0451^{*}$ & $0.177 \pm 0.03^{*}$ & $0.187 \pm 0.03^{*}$ \\
\hline \multicolumn{5}{|c|}{ Birth weight and gestational age (\%) } \\
\hline SGA & 14.28 & 8.00 & 7.50 & 9.20 \\
\hline AGA & 78.57 & 60.00 & 79.00 & 76.92 \\
\hline LGA & 7.15 & 32.00 & 13.50 & 13.88 \\
\hline
\end{tabular}

Note: HbAlc: glycated hemoglobin; BMI-1 and BMI-2: body mass index in the first and third trimester of pregnancy, respectively. Data correspond to the median of 55 mothers and newborns. The ponderal index of a newborn is the cube root of body weight $\times 100$ divided by height in centimeters; the placental index is the ratio of placental weight to fetal weight. SGA: small for gestational age; AGA: adequate for gestational age, and LGA: large for gestational age.

${ }^{*}$ Statistical difference between ND and the other groups.

with 199 medium culture (Sigma Chemical, St. Louis, USA). The cells were used immediately for assays of flow cytometer.

2.5. Cell Subsets. To verify the presence of subsets of NK cells expressing $\mathrm{CD}^{+} 6^{+}$and/or $\mathrm{CD}_{56}{ }^{+}$placenta and blood cells were stained with $5 \mu \mathrm{L}$ of anti-CD $3^{+}$PERCP, anti-CD16 FITC, and anti-CD56 PE, for $30 \mathrm{~min}$ at room temperature. Cells were washed and resuspended in phosphate-buffered saline (PBS) containing bovine serum albumin (BSA; Sigma, ST Louis, USA; $5 \mathrm{mg} / \mathrm{mL}$ ) for flow cytometry analyses. Isotype controls (IgG1-FITC, IgG1-PE both from BD Biosciences) were used. A minimum of 10.000 cells were gated by size (FSC) and granularity (SSC) with a flow cytometer (FACSCalibur, BD Biosciences, USA). Data were analyzed using the Flowjo 7.2 .5 software.

2.6. Quantification of Cytokines. Plasma blood and placenta homogenate were collected and stored at $-80^{\circ} \mathrm{C}$ prior to analyses. The samples were thawed and cytokines [IL- $1 \beta$, IL2, IL-4, IL-6, IL-8, IL-10, IL-12, IL-17, TNF- $\alpha$, and IFN- $\gamma$ ] were measured by cytometric bead array [CBA, BD Biosciences, USA] according to the manufacturer procedures. A flow cytometer was used for these analyses [FACSCalibur, BD Biosciences, USA]. The data were analyzed using the software FCAP Array 1.0 [CBA, BD Biosciences, USA].
2.7. Statistical Analysis. Data were expressed as the mean \pm standard deviation (SD). The statistically significant difference was evaluated using the analysis of variance (ANOVA) for $\mathrm{CD}_{16}{ }^{+}$and $\mathrm{CD}_{5}{ }^{+}$expression and cytokines. Statistical significance was considered for $p<0.05$.

\section{Results}

Clinical data of the mothers and newborns are shown in Table 1 . In the first trimester of pregnancy, DM-2 mothers exhibited the highest body mass index (BMI) and glycemic index $(p<0.05)$. Glycated hemoglobin (HbAlc) levels were higher in GDM and DM-2, and the placental index was higher in the MGH, GDM, and MGH groups. The highest proportion of LGA newborns was found in MGH (Table 1).

The highest content of $\mathrm{CD} 16^{+} \mathrm{CD} 56^{-} \mathrm{NK}$ cells in maternal blood was detected in GDM and DM-2, followed by $\mathrm{MGH}$ (Table 2). In the cord blood, the amount of $\mathrm{CD} 16^{+} \mathrm{CD} 56^{-}$ cells was higher in DM-2, and in the placental villous layer it was similar among the groups. In the placental extravillous layer, GDM and DM-2 contained the highest levels of $\mathrm{CD}^{+} 6^{+} \mathrm{CD}^{-}{ }^{-}$cells (Table 2$)$.

In general, $\mathrm{CD}_{16}{ }^{-} \mathrm{CD}^{+} 6^{+}$cells were similar in maternal blood among the groups. In the cord blood, their frequency was higher in GDM and DM-2. In the placenta, irrespective of the layer, the $\mathrm{CD}^{-} 6^{-} \mathrm{CD} 56^{+}$cell proportion was higher in 
TABLE 2: Percentage of cell phenotypes $\mathrm{CD} 16^{+}$and/or $\mathrm{CD}^{+} 6^{+}$in the placenta, maternal blood, and cord blood of groups without diabetes (ND) or with mild hyperglycemia (MGH), gestational diabetes mellitus (GDM), and diabetes mellitus (DM-2).

\begin{tabular}{|c|c|c|c|c|c|}
\hline Cells (\%) & Sample & $\begin{array}{c}\text { ND } \\
(N=15)\end{array}$ & $\begin{array}{c}\text { MGH } \\
(N=15)\end{array}$ & $\begin{array}{c}\text { DGM } \\
(N=10)\end{array}$ & $\begin{array}{c}\text { DM-2 } \\
(N=15)\end{array}$ \\
\hline \multirow{4}{*}{$\mathrm{CD} 6^{+} \mathrm{CD} 56^{-}$} & Maternal blood & $12.85 \pm 6.73$ & $30.67 \pm 2.50^{*}$ & $84.40 \pm 16.36^{*}$ & $57.27 \pm 5.68^{*}$ \\
\hline & Cord blood & $18.53 \pm 3.11$ & $23.71 \pm 2.16$ & $15.43 \pm 8.59$ & $41.94 \pm 18.98^{*}$ \\
\hline & Placenta villi & $4.70 \pm 2.71$ & $4.70 \pm 2.71$ & $4.19 \pm 3.01$ & $4.76 \pm 2.48$ \\
\hline & Placenta extravilli & $4.85 \pm 3.22$ & $3.45 \pm 1.64$ & $10.65 \pm 2.84^{* \#}$ & $10.20 \pm 6.91^{* \#}$ \\
\hline \multirow{4}{*}{$\mathrm{CD} 16^{-} \mathrm{CD} 56^{+}$} & Maternal blood & $1.36 \pm 0.19$ & $1.90 \pm 0.15$ & $1.45 \pm 0.26$ & $1.45 \pm 0.26$ \\
\hline & Cord blood & $0.50 \pm 0.10$ & $0.38 \pm 0.15$ & $2.76 \pm 0.18^{*}$ & $2.16 \pm 0.18^{*}$ \\
\hline & Placenta villi & $13.37 \pm 5.56$ & $66.74 \pm 20.19^{*}$ & $22.26 \pm 16.11^{*}$ & $5.11 \pm 3.10^{*}$ \\
\hline & Placenta extravilli & $16.49 \pm 7.67$ & $27.56 \pm 13.00^{* \#}$ & $30.17 \pm 19.00^{*}$ & $8.54 \pm 2.15^{*}$ \\
\hline \multirow{4}{*}{$\mathrm{CD} 16^{+} \mathrm{CD} 6^{+}$} & Maternal blood & $8.88 \pm 3.34$ & $6.69 \pm 2.25$ & $3.35 \pm 1.02^{*}$ & $6.70 \pm 2.25$ \\
\hline & Cord blood & $4.66 \pm 2.56$ & $5.87 \pm 1.42$ & $3.32 \pm 2.20^{*}$ & $5.88 \pm 1.41$ \\
\hline & Placenta villi & $3.13 \pm 1.2$ & $4.70 \pm 1.92$ & $4.20 \pm 1.18$ & $1.56 \pm 0.55^{*}$ \\
\hline & Placenta extravilli & $5.00 \pm 1.1$ & $7.46 \pm 1.31^{*}$ & $6.76 \pm 1.04^{* \#}$ & $3.68 \pm 1.47^{* \#}$ \\
\hline
\end{tabular}

Note: results are expressed as the mean of samples of maternal blood, cord blood, and placental tissue. ${ }^{*}$ Statistical difference between ND and the other groups;

${ }^{\#}$ statistical difference between cells in placenta villi and placenta extravilli within the same group.

MGH and GDM and lower in the DM-2 group (Table 2). $\mathrm{CD} 16^{+} \mathrm{CD} 56^{+}$cells were less frequent in maternal blood and cord blood from GDM. In the placenta villous tissue they were lower in DM-2, whereas in placenta extravillous tissue they were higher in MGH and DGM and lower in DM-2 (Table 2).

Cytokines (IL-1 $\beta$, IL-2, IL-4, IL-6, IL-8, IL-10, IL-12, IL-17, TNF- $\alpha$, and IFN- $\gamma$ ) were assessed in the placenta, maternal blood, and cord blood from the groups (Table 3 ). The levels of IL- $1 \beta$ in placenta extravillous tissue were lower in $\mathrm{MGH}$ and GDM. IL-2 levels were lower in the maternal blood from GDM and placenta villi from MGH, whereas IL-4 levels were higher in the cord blood from GDM and placental extravillous layer from MGH (Table 3).

In MGH and GDM, IL-6 concentrations were higher in the placental extravillous layer and lower in placenta villi, and, in DM-2, they were higher in placenta villi. In GDM IL8 levels were higher in placenta irrespective of the layer, and in DM-2 they were lower in the placental extravillous layer. MGH and DM-2 showed lower IL-8 levels in the placental extravillous layer (Table 3). IL-10 levels were higher in the placental extravillous layer from MGH, GDM, and DM-2. IL12 p70 concentrations were higher in the placental extravillous layer from DM-2 (Table 3).

Irrespective of placental section, $\mathrm{TNF}-\alpha$ levels were higher in DM-2 and lower in GDM. IFN- $\gamma$ levels were higher in maternal and cord blood from GDM. Cytokine levels in the placenta were higher in MGH and DM-2. In placenta extravillous tissue IFN- $\gamma$ levels were lower in GDM. In maternal and cord blood, the highest IL-17 levels were found in DM-2, and in the placenta they were higher in MGH and DM-2 (Table 3).

The placenta villous/extravillous cytokine ratio is shown in Table 4. For IL-1 $\beta$, IL-2, and IL-17, it was similar among the groups; for IL-4, it was lower in MGH and DM-2, and for IL-6 it was lower in MGH and GDM. DM-2 exhibited higher villous/extravillous IL-8, TNF- $\alpha$, and IFN- $\gamma$ ratio and lower ratio for IL-12p70. For IL-8, the ratio was lower in GDM; for TNF- $\alpha$ it was lower in GDM and MGH; and for IL-10 it was lower in MGH (Table 4).

\section{Discussion}

Fetal and placental tissues require suitable environment, under homeostasis, whereas the maternal body is affected by factors related to metabolic alterations. The fetus receives passive immunity from the mother, which is crucial for newborn adaptation to the extrauterine environment because it provides protection during the first months of life [2528]. Studies have showed that umbilical cord blood plasma contains soluble NKG2D ligands that alter the Nk function and act as a mechanism of fetal-maternal tolerance in human pregnancy [29]. In the present study we characterized the NK cell and cytokine profile in maternal and cord blood as well as the placenta, showing their differences as a function of hyperglycemic status.

NK cells have distinct phenotypes with different functions in discrete tissues; they mediate immune homeostasis in peripheral blood and secondary lymphoid tissues and regulate uterine vascularization [30]. The present study showed an increase in the subsets of cells expressing the CD16 marker in mothers from DM-2 and GDM. This response was similar in fetuses from DM-2, but not in fetuses from GDM. An interesting result was that cells expressing $\mathrm{CD}^{+} 6^{+}$were frequent in the placental extravillous layer but not in the villous layer. In the peripheral blood, NK cells are typically the largest subset of perforin-expressing cytotoxic lymphocytes and constitute 5 to $15 \%$ of total lymphocytes [31]. However, human uterine NK cells (uNK) are phenotypically CD56 ${ }^{+}$, which are not cytotoxic [4-6].

Other studies report that a large number of uNK cells are necessary to support successful embryo implantation. In general, the two major types of NK cells are CD56 (bright) 
TABLe 3: Cytokine levels (pg/mL) in placental tissue, maternal blood, and cord blood in groups without diabetes (ND) or with mild hyperglycemia (MGH), gestational diabetes mellitus (GDM), and diabetes mellitus (DM-2).

\begin{tabular}{|c|c|c|c|c|c|}
\hline \multirow[b]{2}{*}{ Cytokines } & \multirow[b]{2}{*}{ Samples } & \multicolumn{4}{|c|}{ Concentration $(\mathrm{pg} / \mathrm{mL})$} \\
\hline & & $\begin{array}{c}\mathrm{ND} \\
(N=15)\end{array}$ & $\begin{array}{c}\text { MGH } \\
(N=15)\end{array}$ & $\begin{array}{c}\text { GDM } \\
(N=10)\end{array}$ & $\begin{array}{c}\text { DM-2 } \\
(N=15)\end{array}$ \\
\hline \multirow{4}{*}{ IL-1 $\beta$} & Maternal blood & $16.43 \pm 2.71$ & $16.33 \pm 1.07$ & $16.01 \pm 2.00$ & $16.85 \pm 1.64$ \\
\hline & Cord blood & $15.49 \pm 2.12$ & $15.84 \pm 0.79$ & $16.54 \pm 1.80$ & $14.96 \pm 2.39$ \\
\hline & Placenta villi & $10.78 \pm 4.05$ & $8.24 \pm 0.66$ & $9.68 \pm 1.24$ & $8.24 \pm 0.49$ \\
\hline & Placenta extravilli & $12.14 \pm 4.29$ & $8.23 \pm 2.04^{*}$ & $9.76 \pm 2.27^{*}$ & $10.86 \pm 2.58$ \\
\hline \multirow{4}{*}{ IL-2 } & Maternal blood & $15.34 \pm 4.86$ & $15.37 \pm 3.74$ & $9.76 \pm 0.48^{*}$ & $14.00 \pm 4.02$ \\
\hline & Cord blood & $12.77 \pm 3.20$ & $14.05 \pm 3.76$ & $12.41 \pm 2.74$ & $11.76 \pm 3.61$ \\
\hline & Placenta villi & $10.42 \pm 0.46$ & $7.28 \pm 3.11^{*}$ & $9.34 \pm 3.90$ & $10.05 \pm 3.78$ \\
\hline & Placenta extravilli & $11.10 \pm 1.20$ & $10.21 \pm 2.21$ & $9.48 \pm 0.87$ & $10.70 \pm 3.54$ \\
\hline \multirow{4}{*}{ IL-4 } & Maternal blood & $7.06 \pm 1.82$ & $10.16 \pm 2.87$ & $8.60 \pm 0.93$ & $8.30 \pm 2.16$ \\
\hline & Cord blood & $7.76 \pm 1.97$ & $12.80 \pm 5.90$ & $14.76 \pm 6.58^{*}$ & $9.06 \pm 4.40$ \\
\hline & Placenta villi & $8.93 \pm 0.70$ & $9.93 \pm 3.93$ & $7.84 \pm 3.32$ & $8.35 \pm 0.67$ \\
\hline & Placenta extravilli & $9.34 \pm 0.74$ & $28.81 \pm 13.32^{\text {*\# }}$ & $8.42 \pm 0.82$ & $12.85 \pm 5.05$ \\
\hline \multirow{4}{*}{ IL-6 } & Maternal blood & $16.32 \pm 2.45$ & $15.36 \pm 1.70$ & $16.34 \pm 1.96$ & $15.06 \pm 0.95$ \\
\hline & Cord blood & $16.29 \pm 2.37$ & $16.39 \pm 1.54$ & $16.20 \pm 2.00$ & $14.27 \pm 1.40$ \\
\hline & Placenta villi & $20.29 \pm 13.68$ & $7.93 \pm 0.67^{*}$ & $10.26 \pm 2.83^{*}$ & $47.45 \pm 17.10^{*}$ \\
\hline & Placenta extravilli & $11.82 \pm 4.35^{\#}$ & $35.67 \pm 25.47^{* \#}$ & $39.28 \pm 19.07^{* \#}$ & $10.03 \pm 2.47^{\#}$ \\
\hline \multirow{4}{*}{ IL-8 } & Maternal blood & $24.5 \pm 4.39$ & $24.61 \pm 1.41$ & $25.44 \pm 2.95$ & $24.23 \pm 2.68$ \\
\hline & Cord blood & $26.95 \pm 4.95$ & $26.41 \pm 3.38$ & $28.44 \pm 4.12$ & $23.24 \pm 4.99$ \\
\hline & Placenta villi & $28.77 \pm 19.81$ & $19.32 \pm 5.27$ & $35.57 \pm 12.03^{*}$ & $30.80 \pm 14.33$ \\
\hline & Placenta extravilli & $37.59 \pm 21.26^{\#}$ & $12.93 \pm 5.51^{* \#}$ & $42.73 \pm 24.56^{\#}$ & $22.47 \pm 4.99^{* \#}$ \\
\hline \multirow{4}{*}{ IL-10 } & Maternal blood & $14.75 \pm 1.78$ & $13.91 \pm 1.06$ & $14.21 \pm 1.13$ & $13.95 \pm 0.53$ \\
\hline & Cord blood & $14.40 \pm 0.69$ & $15.33 \pm 1.91$ & $14.58 \pm 0.81$ & $13.38 \pm 1.06$ \\
\hline & Placenta villi & $13.59 \pm 5.49$ & $10.42 \pm 2.74$ & $9.08 \pm 3.74^{*}$ & $13.89 \pm 6.98$ \\
\hline & Placenta extravilli & $10.66 \pm 4.95^{\#}$ & $26.45 \pm 13.16^{* \#}$ & $26.51 \pm 8.70^{* \#}$ & $27.16 \pm 5.45^{* \#}$ \\
\hline \multirow{4}{*}{ IL-12p70 } & Maternal blood & $10.89 \pm 2.37$ & $11.78 \pm 4.46$ & $11.37 \pm 2.07$ & $9.59 \pm 1.05$ \\
\hline & Cord blood & $10.51 \pm 1.25$ & $11.79 \pm 1.36$ & $10.19 \pm 0.52$ & $11.19 \pm 0.90$ \\
\hline & Placenta villi & $5.39 \pm 1.22$ & $5.76 \pm 1.04$ & $8.59 \pm 4.81$ & $10.68 \pm 4.94$ \\
\hline & Placenta extravilli & $4.74 \pm 0.51$ & $7.9 \pm 1.09$ & $10.06 \pm 3.60$ & $15.34 \pm 0.59^{* \#}$ \\
\hline \multirow{4}{*}{ TNF } & Maternal blood & $13.78 \pm 2.82$ & $13.27 \pm 1.73$ & $13.72 \pm 1.67$ & $13.34 \pm 1.20$ \\
\hline & Cord blood & $13.74 \pm 0.91$ & $14.28 \pm 1.15$ & $12.54 \pm 0.80$ & $11.76 \pm 0.75$ \\
\hline & Placenta villi & $7.48 \pm 1.17$ & $12.77 \pm 5.18$ & $8.88 \pm 1.91$ & $28.69 \pm 13.82^{*}$ \\
\hline & Placenta extravilli & $10.61 \pm 3.06^{\#}$ & $14.36 \pm 5.27$ & $9.11 \pm 4.51$ & $17.99 \pm 6.34^{* \#}$ \\
\hline \multirow{4}{*}{ IFN- $\gamma$} & Maternal blood & $6.37 \pm 0.99$ & $6.40 \pm 0.71$ & $22.83 \pm 4.47^{*}$ & $6.80 \pm 1.55$ \\
\hline & Cord blood & $6.47 \pm 0.99$ & $17.05 \pm 0.17$ & $37.15 \pm 11.98^{*}$ & $8.45 \pm 3.88$ \\
\hline & Placenta villi & $6.63 \pm 1.02$ & $12.88 \pm 5.64^{*}$ & $7.27 \pm 0.15$ & $19.95 \pm 4.37^{*}$ \\
\hline & Placenta extravilli & $7.48 \pm 1.18$ & $14.11 \pm 7.95^{*}$ & $4.21 \pm 2.14^{* \#}$ & $16.59 \pm 4.92^{*}$ \\
\hline \multirow{4}{*}{ IL-17A } & Maternal blood & $6.98 \pm 1.11$ & $7.08 \pm 2.93$ & $8.90 \pm 2.45$ & $16.20 \pm 4.39^{*}$ \\
\hline & Cord blood & $5.25 \pm 1.17$ & $5.35 \pm 0.26$ & $8.67 \pm 1.76^{*}$ & $15.46 \pm 2.78^{*}$ \\
\hline & Placenta villi & $5.15 \pm 2.40$ & $16.86 \pm 5.64^{*}$ & $5.11 \pm 1.23$ & $17.49 \pm 5.39^{*}$ \\
\hline & Placenta extravilli & $5.63 \pm 0.91$ & $14.03 \pm 4.78^{*}$ & $7.69 \pm 5.14$ & $14.42 \pm 7.20^{*}$ \\
\hline
\end{tabular}

Note: results are expressed as the mean of samples of maternal blood, cord blood, and placental tissue. * Statistical difference between ND and the other groups; \# statistical difference between cells in placenta villi and placenta extravilli within the same group. 
TABLE 4: Placental villous/extravillous cytokine ratio in groups without diabetes (ND) or with mild hyperglycemia (MGH), gestational diabetes mellitus (GDM), and diabetes mellitus (DM-2).

\begin{tabular}{lcccc}
\hline \multirow{2}{*}{$\begin{array}{l}\text { Placental } \\
\text { cytokines }\end{array}$} & \multicolumn{4}{c}{ Villous layer/extravillous layer ratio } \\
& ND & MGH & GDM & DM-2 \\
& $(N=15)$ & $(N=15)$ & $(N=10)$ & $(N=15)$ \\
\hline IL-1 $\beta$ & $0.68 \pm 0.23$ & $1.04 \pm 0.21$ & $1.05 \pm 0.18$ & $0.79 \pm 0.15$ \\
IL-2 & $0.94 \pm 0.07$ & $0.86 \pm 0.17$ & $1.00 \pm 0.28$ & $1.02 \pm 0.34$ \\
IL-4 & $2.13 \pm 1.09$ & $0.45 \pm 0.29^{*}$ & $1.27 \pm 0.38$ & $0.70 \pm 0.23^{*}$ \\
IL-6 & $1.13 \pm 0.42$ & $0.68 \pm 0.15^{*}$ & $0.45 \pm 0.08^{*}$ & $1.02 \pm 0.22$ \\
IL-8 & $0.75 \pm 0.41$ & $0.92 \pm 0.20$ & $0.25 \pm 0.08^{*}$ & $3.60 \pm 1.90^{*}$ \\
IL-10 & $1.33 \pm 0.58$ & $0.52 \pm 0.21^{*}$ & $0.90 \pm 0.35$ & $0.75 \pm 0.44$ \\
IL-12 & $1.36 \pm 0.75$ & $1.41 \pm 0.95$ & $1.40 \pm 1.14$ & $0.80 \pm 0.33^{*}$ \\
IL-17 & $1.11 \pm 0.49$ & $1.33 \pm 0.56$ & $0.98 \pm 0.20$ & $1.50 \pm 0.64$ \\
TNF- $\alpha$ & $0.84 \pm 0.13$ & $0.83 \pm 0.27^{*}$ & $0.36 \pm 0.10^{*}$ & $1.50 \pm 0.64^{*}$ \\
IFN- $\gamma$ & $0.80 \pm 0.09$ & $1.23 \pm 0.74$ & $0.64 \pm 0.20$ & $1.25 \pm 0.28^{*}$ \\
\hline
\end{tabular}

Note: results are expressed as the mean of samples of placental tissue. ${ }^{*}$ Statistical difference between ND and the other groups.

and CD56 (dim) cells. Most CD56 (bright) cells are not found in peripheral circulation but reside almost exclusively in the secondary lymph tissue, and their main activity is the production of cytokines, which increases the number of inhibitory receptors in decidual NK cells, maintaining the nonactivated phenotype $\left(\mathrm{CD} 16^{-} \mathrm{CD}^{+} 6^{+}\right)[7,8]$.

In the present study, the subsets of cells expressing $\mathrm{CD} 56^{+}$ in placenta were higher in MGH and GDM and less frequent in DM-2. The molecular mechanisms determining NK cell phenotype have yet to be elucidated [32]. NK cells in the human uterus ( $\mathrm{uNK}$ ) and decidua (dNK) have a unique functional profile. They participate in tissue remodeling and neoangiogenesis, regulating fetal trophoblast invasion, placental vascularization, and especially cytokine and chemokine production $[8,33]$. Studies showed that women with GDM have abnormal NK cell function due expression of surface receptors and cytokine production [34], whereas in women with type I diabetes mellitus alterations occur in immunological balances during pregnancy with proinflammatory systemic environment and greatest impact on CD56 Nk cells [35]. In the present study, the increase in $\mathrm{CD}^{+} 6^{+}$and decrease in $\mathrm{CD}_{56}{ }^{+}$cell expression in the placenta from DM2 suggest intensification of the innate immune response in diabetic mothers, possibly modulated by the secretion of proinflammatory cytokines that stimulate the NK cells [36]. Both pro- and anti-inflammatory cytokines have the ability to affect the activity of NK cells [37].

The hyperglycemia status of the women under study affected the cytokine profile in maternal blood and placental tissue. In GDM and DM-2, the levels of inflammatory cytokines such as IFN- $\gamma$ and IL-17 were higher in maternal and cord blood. Similarly, earlier studies showed that mild gestational diabetes and gestational diabetes affect IFN $-\gamma$ in cord blood and IL-17 in maternal blood, suggesting that IL-17 is an important immunological indicator of inflammation during diabetes progression [17].
Major changes in cytokine levels were observed in the placenta and were associated with its layer (extravillous layer at the maternal interface and villous layer at the fetal interface). In fact, in DM-2 the maternal portion of placenta contained high levels of IL-12, IL-17, TNF- $\alpha$, and IFN- $\gamma$, and the fetal interface had high levels of IL-6, TNF- $\alpha$, IL-17, and IFN- $\gamma$, indicating that the fetal environment is supplied with inflammatory cytokines. This inflammatory profile was weaker in placentas from GDM and MGH. In MGH, placental levels of IL- $1 \beta$ and IL- 8 were low but those of IL-6, IL-17, and IFN- $\gamma$ were high. In placenta villi in GDM, despite the high IL-8 levels, the concentration of IL-10 was low. Low placental IL-10 levels have been associated with fetal loss, premature delivery, and preeclampsia, irrespective of the prevalence of maternal diabetes [38].

In a previous study it was found that placental TNF- $\alpha$ levels are higher in diabetic women, suggesting that the previous inflammatory and hyperglycemic environment stimulates placental production of TNF- $\alpha$ in a full-term pregnancy [15]. TNF- $\alpha$ production by immune cells in response to different inflammatory stimuli is enhanced by membrane rupture in complicated pregnancies [21,39].

Cytokine IL-12 is reported to potentiate IFN- $\gamma$ production by NK cells $[40,41]$, which is likely related to the higher number of cells expressing $\mathrm{CD}^{+} 6^{+}$in the placenta of diabetic mothers (DM-2). One remarkable result is that the villous/ extravillous IFN- $\gamma$ and TNF- $\alpha$ ratio was higher in DM-2 placenta. It should be considered that during pregnancy immunological adaptations occur, but the hyperglycemia can alter these adaptations and be responsible for the greater frequency of complications in pregnant women with diabetes [42].

This finding corroborates the hypothesis that the placenta is capable of modifying the concentrations of cells and cytokines from the maternal blood before transferring them to the fetus and that this activity is affected by the inflammatory environment produced by hyperglycemia. An appropriate pro- or anti-inflammatory cytokine balance in decidua is required to support fetal development and must therefore be preserved during antimicrobial responses to prevent inflammation-induced tissue damage and maintain a successful pregnancy [21].

\section{Conclusion}

In conclusion, the levels of cells expressing $\mathrm{CD}^{+} 6^{+}$and cytokines in maternal blood, cord blood, and placental tissue are modified in pregnancies complicated by diabetes. Diabetic mothers release a larger amount of cytokines, indicating their important role in regulating the immune response during pregnancy. Despite our findings, changes in the profile of NK cells and cytokines in the placenta of patients with different types of hyperglycemia deserve further attention, given their function over the course of pregnancy.

\section{Competing Interests}

The authors declare no nonfinancial or any other competing interests. 


\section{Acknowledgments}

The authors are very grateful to the Diabetes and Pregnancy Service, Obstetrics Discipline of Botucatu Medical School, UNESP. This research was supported by FAPESP (no. 2012/ 24212-4 and no. 2013/13017-9), FAPEMAT (no. 158085/2014), and CNPq (no. 308702/2013-1 and no. 475238/2013-3).

\section{References}

[1] G. J. King, "Comparative placentation in ungulates," Journal of Experimental Zoology, vol. 266, no. 6, pp. 588-602, 1993.

[2] I. Guleria and M. H. Sayegh, "Maternal acceptance of the fetus: true human tolerance," Journal of Immunology, vol. 178, no. 6, pp. 3345-3351, 2007.

[3] L. A. Salamonsen and L. J. Lathbury, "Endometrial leukocytes and menstruation," Human Reproduction Update, vol. 6, no. 1, pp. 16-27, 2000.

[4] X. F. Li, D. S. Charnock-Jones, E. Zhang et al., "Angiogenic growth factor messenger ribonucleic acids in uterine natural killer cells," The Journal of Clinical Endocrinology and Metabolism, vol. 86, no. 4, pp. 1823-1834, 2001.

[5] S. Kalkunte, C. O. Chichester, F. Gotsch, C. L. Sentman, R. Romero, and S. Sharma, "Evolution of non-cytotoxic uterine natural killer cells," American Journal of Reproductive Immunology, vol. 59, no. 5, pp. 425-432, 2008.

[6] V. Male, A. Sharkey, L. Masters, P. R. Kennedy, L. E. Farrell, and A. Moffett, "The effect of pregnancy on the uterine NK cell KIR repertoire," European Journal of Immunology, vol. 41, no. 10, pp. 3017-3027, 2011.

[7] N. Rouas-Freiss, R. M.-B. Gonçalves, C. Menier, J. Dausset, and E. D. Carosella, "Direct evidence to support the role of HLA$\mathrm{G}$ in protecting the fetus from maternal uterine natural killer cytolysis," Proceedings of the National Academy of Sciences of the United States of America, vol. 94, no. 21, pp. 11520-11525, 1997.

[8] A. Moffett-King, "Natural killer cells and pregnancy," Nature Reviews Immunology, vol. 2, no. 9, pp. 656-663, 2002.

[9] S. Shigeru, N. Akitoshi, M.-H. Subaru, and A. Shiozaki, "The balance between cytotoxic NK cells and regulatory NK cells in human pregnancy," Journal of Reproductive Immunology, vol. 77, no. 1, pp. 14-22, 2008.

[10] R. Raghupathy, "Th1-type immunity is incompatible with successful pregnancy," Immunology Today, vol. 18, no. 10, pp. 478482, 1997.

[11] M. T. Coughlan, K. Oliva, H. M. Georgiou, J. M. H. Permezel, and G. E. Rice, "Glucose-induced release of tumour necrosis factor-alpha from human placental and adipose tissues in gestational diabetes mellitus," Diabetic Medicine, vol. 18, no. 11, pp. 921-927, 2001.

[12] J. C. Peraçoli, M. V. C. Rudge, and M. T. S. Peraçoli, “Tumor necrosis factor-alpha in gestation and puerperium of women with gestational hypertension and pre-eclampsia," American Journal of Reproductive Immunology, vol. 57, no. 3, pp. 177-185, 2007.

[13] J. M. Denney, E. L. Nelson, P. D. Wadhwa et al., "Longitudinal modulation of immune system cytokine profile during pregnancy," Cytokine, vol. 53, no. 2, pp. 170-177, 2011.

[14] J. B. Moreli, G. Morceli, A. K. C. De Luca et al., "Influence of maternal hyperglycemia on IL-10 and TNF- $\alpha$ production: the relationship with perinatal outcomes," Journal of Clinical Immunology, vol. 32, no. 3, pp. 604-610, 2012.
[15] J. B. Moreli, S. Corrêa-Silva, D. C. Damasceno et al., "Changes in the TNF-alpha/IL-10 ratio in hyperglycemia-associated pregnancies," Diabetes Research and Clinical Practice, vol. 107, no. 3, pp. 362-369, 2015.

[16] M. Pertyńska-Marczewska, E. Głowacka, A. Grodzicka et al., "Profile of peripheral blood neutrophil cytokines in diabetes type 1 pregnant women and its correlation with selected parameters in the newborns," American Journal of Reproductive Immunology, vol. 63, no. 2, pp. 150-160, 2010.

[17] D. L. Gomes Fagundes, E. L. França, R. T. da Silva Fernandes et al., "Changes in T-cell phenotype and cytokines profile in maternal blood, cord blood and colostrum of diabetic mothers," The Journal of Maternal-Fetal \& Neonatal Medicine, vol. 29, no. 6, pp. 998-1004, 2016.

[18] American Diabetes Association, "Diagnosis and classification of diabetes mellitus," Diabetes Care, vol. 35, pp. S64-S71, 2012.

[19] M. V. C. Rudge, I. D. M. P. Calderon, M. D. Ramos, J. F. Abbade, and L. M. S. S. Rugolo, "Perinatal outcome of pregnancies complicated by diabetes and by maternal daily hyperglycemia not related to diabetes: a retrospective 10-year analysis," Gynecologic and Obstetric Investigation, vol. 50, no. 2, pp. 108-112, 2000.

[20] I. M. P. Calderon, D. C. Damasceno, R. L. Amorin, R. A. A. Costa, M. A. M. Brasil, and M. V. C. Rudge, "Morphometric study of placental villi and vessels in women with mild hyperglycemia or gestational or overt diabetes," Diabetes Research and Clinical Practice, vol. 78, no. 1, pp. 65-71, 2007.

[21] M. Duriez, H. Quillay, Y. Madec et al., "Human decidual macrophages and NK cells differentially express Toll-like receptors and display distinct cytokine profiles upon TLR stimulation," Frontiers in Microbiology, vol. 5, article 316, 14 pages, 2014.

[22] Z. L. Vincent, M. D. Mitchell, and A. P. Ponnampalam, "Regulation of MT1-MMP/MMP-2/TIMP-2 axis in human placenta," Journal of Inflammation Research, vol. 8, pp. 193-200, 2015.

[23] A.-C. Stenqvist, T. Chen, M. Hedlund et al., "An efficient optimized method for isolation of villous trophoblast cells from human early pregnancy placenta suitable for functional and molecular studies," American Journal of Reproductive Immunology, vol. 60, no. 1, pp. 33-42, 2008.

[24] A. U. Borbely, S. Sandri, I. R. Fernandes et al., "The term basal plate of the human placenta as a source of functional extravillous trophoblast cells," Reproductive Biology and Endocrinology, vol. 12, article 7, 2014.

[25] E. L. França, I. D. M. P. Calderon, E. L. Vieira, G. Morceli, and A. C. Honorio-França, "Transfer of maternal immunity to newborns of diabetic mothers," Clinical and Developmental Immunology, vol. 2012, Article ID 928187, 7 pages, 2012.

[26] G. Morceli, E. L. França, V. B. Magalhães, D. C. Damasceno, I. M. P. Calderon, and A. C. Honorio-França, "Diabetes induced immunological and biochemical changes in human colostrum," Acta Paediatrica, International Journal of Paediatrics, vol. 100, no. 4, pp. 550-556, 2011.

[27] G. Morceli, A. C. Honorio-França, D. L. G. Fagundes, I. M. P. Calderon, and E. L. França, "Antioxidant effect of melatonin on the functional activity of colostral phagocytes in diabetic women," PLoS ONE, vol. 8, no. 2, Article ID e56915, 2013.

[28] D. L. G. Fagundes, E. L. França, G. Morceli, M. V. C. Rudge, I. D. M. P. Calderon, and A. C. Honorio-França, "The role of cytokines in the functional activity of phagocytes in blood and colostrum of diabetic mothers," Clinical and Developmental Immunology, vol. 2013, Article ID 590190, 8 pages, 2013. 
[29] S. T. Cox, R. Laza-Briviesca, H. Pearson et al., "Umbilical cord blood plasma contains soluble NKG2D ligands that mediate loss of natural killer cell function and cytotoxicity," European Journal of Immunology, vol. 45, no. 8, pp. 2324-2334, 2015.

[30] F. Cichocki, E. Sitnicka, and Y. T. Bryceson, "NK cell development and function-plasticity and redundancy unleashed," Seminars in Immunology, vol. 26, no. 2, pp. 114-126, 2014.

[31] S. C. C. Chiang, J. Theorell, M. Entesarian et al., "Comparison of primary human cytotoxic T-cell and natural killer cell responses reveal similar molecular requirements for lytic granule exocytosis but differences in cytokine production," Blood, vol. 121, no. 8, pp. 1345-1356, 2013.

[32] A. S. Cerdeira, A. Rajakumar, C. M. Royle et al., "Conversion of peripheral blood NK cells to a decidual NK-like phenotype by a cocktail of defined factors," The Journal of Immunology, vol. 190, no. 8, pp. 3939-3948, 2013.

[33] J. Hanna, D. Goldman-Wohl, Y. Hamani et al., "Decidual NK cells regulate key developmental processes at the human fetalmaternal interface," Nature Medicine, vol. 12, no. 9, pp. 10651074, 2006.

[34] H. Chiba, A. Fukui, K. Fuchinoue, A. Funamizu, K. Tanaka, and H. Mizunuma, "Expression of natural cytotoxicity receptors on and intracellular cytokine production by NK cells in women with gestational diabetes mellitus," American Journal of Reproductive Immunology, vol. 75, no. 5, pp. 529-538, 2016.

[35] S. D. Burke, A. V. C. Seaward, H. Ramshaw et al., "Homing receptor expression is deviated on $\mathrm{CD}^{+} 6^{+}$blood lymphocytes during pregnancy in Type 1 diabetic women," PLoS ONE, vol. 10, no. 3, article e0119526, 2015.

[36] G. Chaouat, S. Dubanchet, and N. Ledée, "Cytokines: important for implantation?" Journal of Assisted Reproduction and Genetics, vol. 24, no. 11, pp. 491-505, 2007.

[37] D. L. Schminkey and M. Groer, "Imitating a stress response: a new hypothesis about the innate immune system's role in pregnancy," Medical Hypotheses, vol. 82, no. 6, pp. 721-729, 2014.

[38] J. E. Thaxton and S. Sharma, "Interleukin-10: a multi-faceted agent of pregnancy," American Journal of Reproductive Immunology, vol. 63, no. 6, pp. 482-491, 2010.

[39] S.-L. Opsiøn, D. Novick, N. C. Wathen, A. P. Cope, D. Wallach, and D. Aderka, "Soluble tumor necrosis factor receptors and soluble interleukin- 6 receptor in fetal and maternal sera, coelomic and amniotic fluids in normal and pre-eclamptic pregnancies," Journal of Reproductive Immunology, vol. 29, no. 2, pp. 119-134, 1995.

[40] T. A. Fehniger, M. H. Shah, M. J. Turner et al., "Differential cytokine and chemokine gene expression by human NK cells following activation with IL-18 or IL-15 in combination with IL-12: implications for the innate immune response," Journal of Immunology, vol. 162, no. 8, pp. 4511-4520, 1999.

[41] M. Vitale, A. Bassini, P. Secchiero et al., "NK-active cytokines IL-2, IL-12, and IL-15 selectively modulate specific protein kinase C (PKC) isoforms in primary human NK cells," Anatomical Record, vol. 266, no. 2, pp. 87-92, 2002.

[42] B. Groen, A. E. van der Wijk, P. P. van den Berg et al., "Immunological adaptations to pregnancy in women with type 1 diabetes," Scientific Reports, vol. 5, Article ID 13618, 2015. 


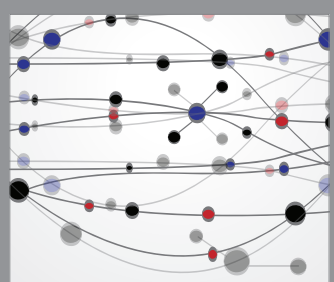

The Scientific World Journal
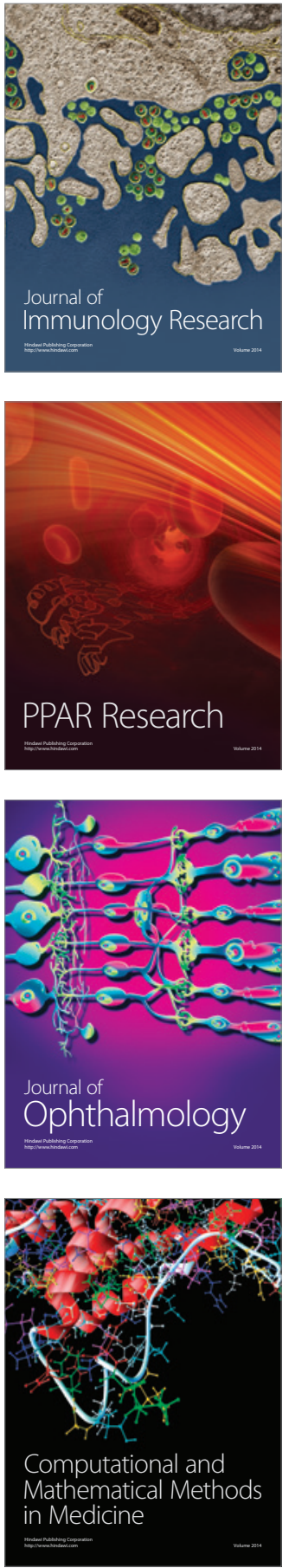

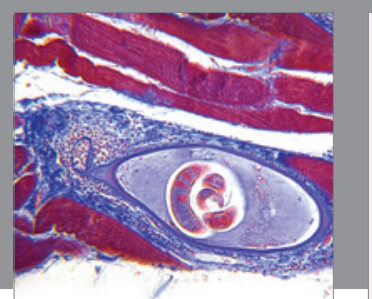

Gastroenterology Research and Practice

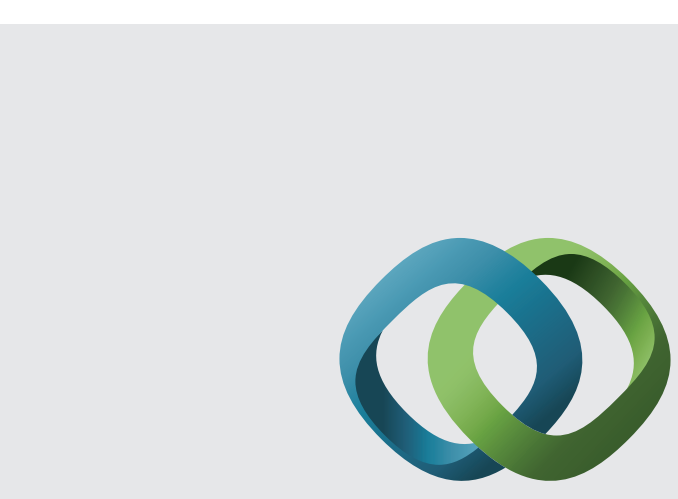

\section{Hindawi}

Submit your manuscripts at

http://www.hindawi.com
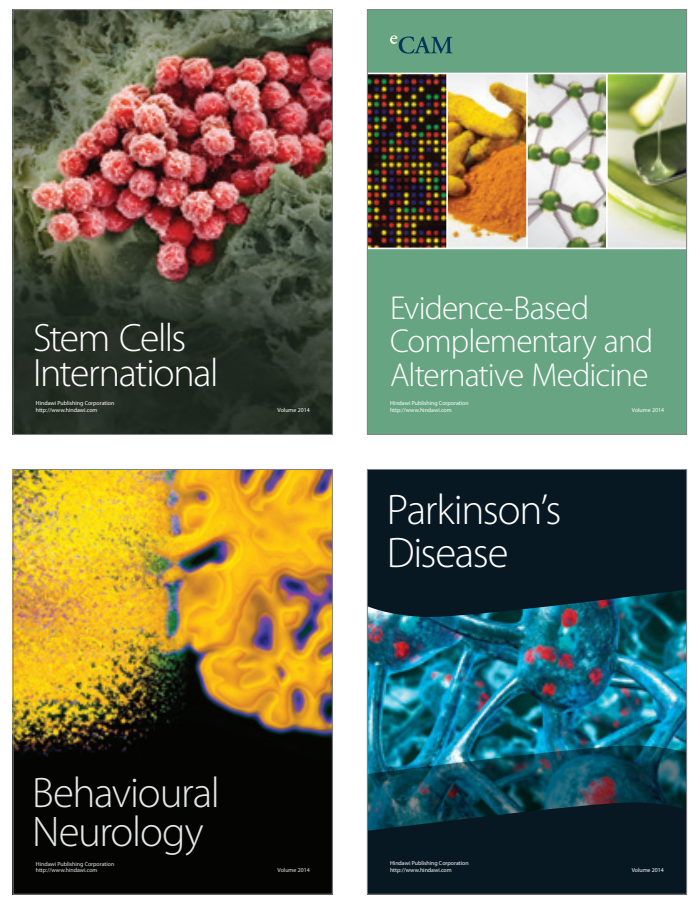
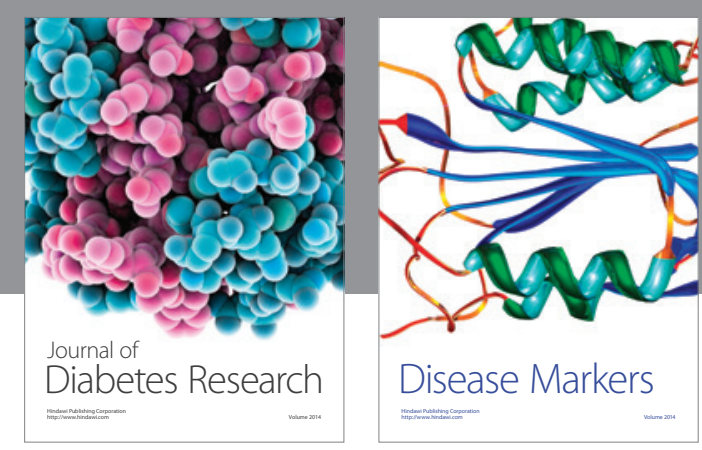

Disease Markers
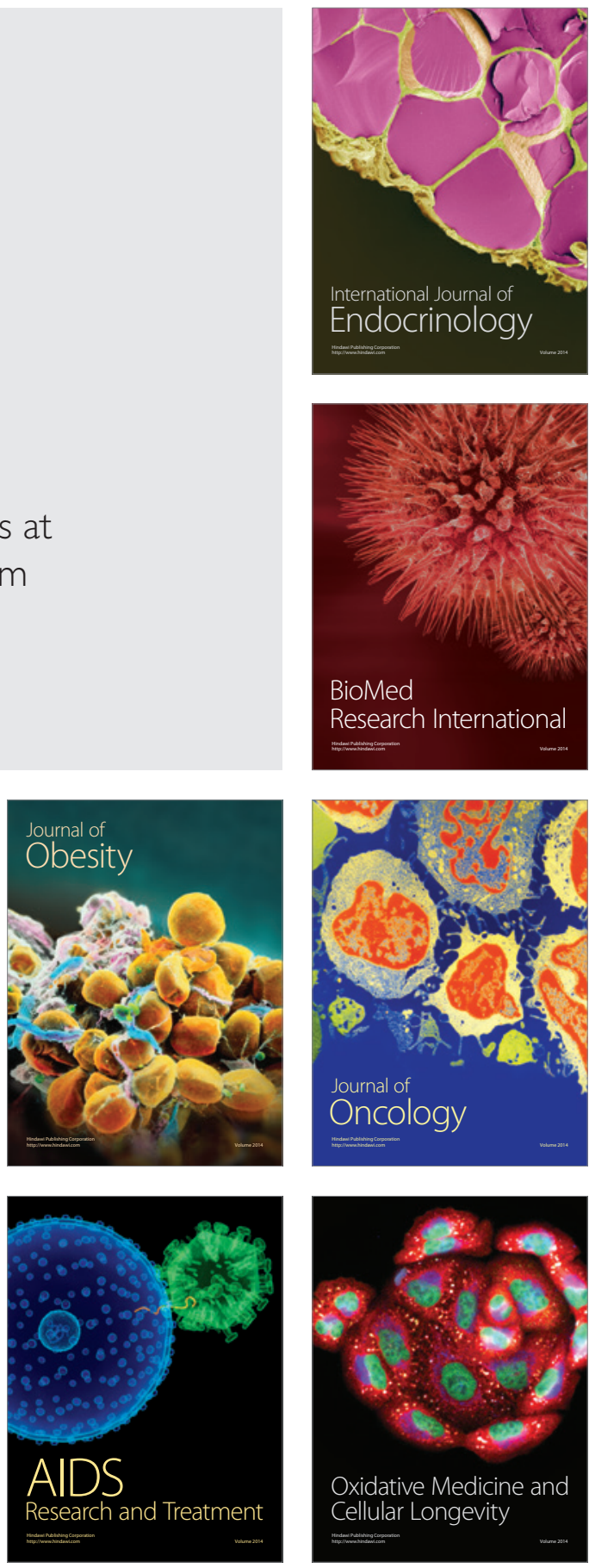